\title{
European Joint Doctorates: myth or reality?
}

\author{
Pilar Coy ${ }^{1}$, Sebastián Cánovas ${ }^{1}$, Ann Van Soom ${ }^{2}$, Nicola Bernabo ${ }^{3}$, Patrick Lonergan 4 , \\ Karl Schellander 5 \\ ${ }^{1}$ Department of Physiology, Universityof Murcia, Spain; ${ }^{2}$ Department of Reproduction \\ Obstetrics and Herd Health, University of Ghent, Belgium; ${ }^{3}$ Faculty of Bioscience, \\ University of Teramo, Italy; ${ }^{4}$ School of Agriculture and Food Science, University College \\ Dublin, Ireland; ${ }^{5}$ Institute of Animal Science, University of Bonn.
}

\begin{abstract}
Today, there is a lack of consensus for the full implementation of common programmes recognizing the "highest" level of higher education in Europe. Even though cotuttelle agreements are widely used for international joint supervision of PhD theses, these are merely bilateral and individual casebased agreements, far away from a real joint degree under a legal framework that establishes the programme. This article aims to describe the experience of the authors in the management and coordination of a joint doctoral programme between 2015 and 2019 and the results obtained from the interrogation of official websites about the reality in Europe concerning such programmes. Our conclusion is that, still in the 21st century, there is a huge gap to be overcome before the existence of Joint International/European Doctorates can be considered an everyday reality. Although various attempts have been made in the last 20 years, there is still a long way to go for Higher Education institutions to integrate all aspects of such programmes, and to make them something more and different than an additional Diploma Supplement. In the authors' opinion, major efforts must be made by the administrative bodies, although the drive of the academic staff is crucial for success.
\end{abstract}

Keywords: European/International Joint Doctorates; Erasmus Mundus; Marie-Sklodowska Curie ITN; European Higher Education Area. 


\section{Introduction}

Starting in 1999, with the launching of the so called "Bologna Process"1, and continuing in 2010, with the implementation of the European Higher Education Area (EHEA), different strategies have been followed by the European Commision (EC) in order to promote the development of common programmes within the three cycles of the University educational system: Bachelor's, Master's and Doctorate. The high success of one of these strategies in the first cycle degree (Bachelor's), regarding the establishment of the joint credit system, can be inferred by the number of undergraduates studying abroad every year under the umbrella of the European Region Action Scheme for the Mobility of University Students (ERASMUS). This is, indeed, the EU's flagship programme for education, training, youth and sport and, according to the 2018 evaluation report (European Commission, 2018), the programme funded learning mobility for more than 4.3 million young people between 2007 and 2016, aiming to reach 1.8 million additional individuals 3 years later. Although not initially conceived as a mechanism to achieve joint degrees, the reality is that the implementation of the joint credit system (ECTS) has allowed students from the 48 countries subscribing to the agreement, to combine, in their curricula, subjects learned in different universities and, at the end of the course, all of them are reflected in one unique degree awarded

As for the second cycle (Master's), it is also very frequent for students to acknowledge Erasmus opportunities, mainly those for traineeships abroad (more than 880.000 practitioners were funded in the same period 2007-2016) but also those included in the Erasmus Mundus Joint Master Degrees (EMJMD) $)^{2}$, with a total of 127 programmes being offered in the academic year 2020-21 ${ }^{3}$ and more than 18,600 Master's scholarships funded from 2004 to $2015^{4}$.

In contrast, at the Doctoral level, there is still a lack of consensus regarding the full implementation of common programmes recognizing the "highest" level of higher education. Even though the cotuttelle agreements are widely used for international joint supervision of $\mathrm{PhD}$ theses, these are merely bilateral and individual case-based agreements, between two specific centres for a specific thesis, and far away from a real joint degree under a legal framework that establishes the programme. Hence, the European Joint Doctorates, first

\footnotetext{
${ }^{1}$ European Higher Education Area and Bologna Process. Retrieved January 20, 2020, from http://www.ehea.info/.

${ }^{2}$ Erasmus Mundus Joint Master Degrees - European Commission. Retrieved January 20, 2020, from https://ec.europa.eu/programmes/erasmus-plus/opportunities/individuals/students/erasmus-mundus-joint-master-degrees_en

${ }^{3}$ EMJMD Catalogue - European Commission. Retrieved January 20, 2020, from https://eacea.ec.europa.eu/erasmusplus/library/scholarships-catalogue_en

${ }^{4}$ Joint Programmes: the story of Erasmus Mundus - Blog. Retrieved January 20, 2020, from https://www.eaie.org/blog/jointprogrammes-story-erasmus-mundus.html
} 
included by the EC in the Erasmus call (until 2013) ${ }^{5}$ and later moved to the MarieSklodowska Curie (MSC) actions (namely MSC-ITN-EJD since the launchiof the Horizon 2020 call), were created with the objective of "promoting international, intersectoral and multi/inter-disciplinary collaboration in doctoral-level training in Europe through the creation of joint doctoral programmes, leading to the delivery of joint, double or multiple doctoral degrees"6.

According to the definition on the $\mathrm{EC} \mathrm{portal}^{6}$, a joint degree is "a single diploma issued by at least two higher education institutions offering an integrated programme and officially recognised in the countries where the degree-awarding institutions are located". In contrast, a double or multiple degree refers to "two or more national diplomas issued by two or more higher education institutions and recognised officially in the countries where the degreeawarding institutions are located". That is, while in the joint degree an integrated structure is implemented at the academic and administrative level, in the double or multiple degrees this does not happen, with the degrees being merely officially recognised by 2 or more institutions.

Bearing in mind that the total EJD programmes under the Erasmus Mundus framework funded 1400 doctoral fellowships between 2004-2015 ${ }^{4}$ and that the MSC actions have subsidized approximately 10 programmes per year since 2014, with a maximum of 15 scholarships per programme (900 students in total), we could infer that, in the last 16 years, a total of 2300 students could have been awarded a Joint $\mathrm{PhD}$ degree. But the question remaining is: how many of them really got a joint diploma and how many, having followed an international, intersectoral, multi/inter-disciplinary, highly prestigious and integrated study programme ended up with a double or multiple degree? Even more, assuming that the majority of them have got a double or multiple degree instead of a joint degree, which are the reasons for such a paradox in the framework of European funded projects? Are the causes related to the difficulty of academic staff to agree about the acquisition of competences by the students, or are they more administration- related issues?

The following text will try to respond to these questions from the experience of the authors in the management and coordination of one such MSC-ITN-EJD programme between 2015 and 2019.

\footnotetext{
${ }^{5}$ Erasmus Mundus Joint Doctorates \& PhD opportunities. Retrieved January 20, 2020, from https://www.em-a.eu/en/erasmusmundus/erasmus-mundus-joint-doctorates.html

${ }^{6}$ Single Electronic Data Interchange Area - European Commission. Retrieved January 20, 2020, from https://ec.europa.eu/info/funding-tenders/opportunities/portal/screen/opportunities/topic-details/msca-itn.
} 


\section{What can be learnt from the previous experience of the Erasmus Mundus doctoral programmes?}

A systematic search performed on the 41 EMJDP included in the list available from the European Consortium for Accreditation $\left(\mathrm{ECA}^{7}\right)$, showed that just 13 of those programmes (32\%) proposed to award a Joint Degree to their graduates (Table 1). Programmes indicating the delivery of Joint/Double degrees under co-tutelle modality have not been included since, as previously explained, this structure does not correspond to the definition of a Joint degree. These data do not indicate that all of them had this objective, but it shows that a low proportion of the funded EMJDP considered, at the time of the proposal submission, that a Joint Degree was a viable option. Information about MSC-ITN-EJD has not been found nor, to our knowledge, is available at public official websites.

\section{The European Joint Doctorate in Biology and Technology of Reproductive Health: a history of successes and failures.}

\subsection{Origin and Structure of the Programme: REPBIOTECH is funded by the EC}

The European Joint Doctorate in Biology and Technology of Reproductive Health (REPBIOTECH) was initiated in 2016 under an agreement signed by 5 European Universities. It was the direct consequence of a compulsory deliverable required by the MSCITN-EJD grants, but it was, at the same time, the result of years of collaboration between scientists enrolled in the proposal whose origins were established in a former Master's Degree Programme developed by the coordinating institution. After years of student exchanges, visits by academics and researchers, and common publications, the proposal for a Joint Doctorate was being shaped and was first submitted under the EMJDP call. It was rejected and, the next year, this call was no longer launched. Therefore, the project was modified and adapted to the MSC-ITN-EJD call and got funded at the second attempt.

REPBIOTECH was always designed to fullfil all the "musts" to become a Joint International Doctorate according to the definition given by de Rosa (2010) that included issues regarding a) Administration and Management, b) Training and Structure, and c) Quality Control and Evaluation System. As has been said, the consortium was composed of 5 European Universities acting as factual beneficiaries, although the 10 associated partners involved played a role very similar to that of the beneficiaries. They consisted of 7 leading academic research groups and 3 private companies from 9 different countries: Spain, France, Ireland, Italy, Belgium, Germany, USA, Japan and Netherlands.

\footnotetext{
${ }^{7}$ http://ecahe.eu/w/index.php/Erasmus_Mundus_Doctorates
} 
Table 1. Doctoral programmes funded under the Erasmus Mundus call aiming to deliver a Joint Doctoral Degree to their graduates at the time of the proposal application.

\section{Programme Comments about the degree awarded}

AgTraIn It is the ambition of the AgTraIn programme to issue joint degrees as soon as the national legislation allows it, in order to truly reflect the integrated nature and common rules, management and quality criteria of the programme. http://www.agtrain.eu.

ETeCoS3 Successful completion of the PhD programme will be awarded a fully recognized and accredited joint Doctoral Degree in Environmental Technology.http://www.internationaldoctorate.unicas.it.

EUDIME - The successful candidates will be awarded a fully recognized multiple and/or a joint degree issued by three consortium institutions (Home University and two Hosting Universities), completed by a diploma supplement. http://eudime.unical.it.

EUROSPIN Each $\mathrm{PhD}$ candidate will pursue an interdisciplinary research project leading to a joint or a double $\mathrm{PhD}$ degree from two universities. http://www.kth.se/en/studies/phd/joint-doctorate/eurospin.

SETS Their research is conducted in at least two of the three universities awarding the joint degree. http://www.setsjointdoctorate.eu.

SMDTex The national PhD degrees of the three involved countries will be delivered to each student after the success of his/her final examination. Based on the experience of this programme, a joint doctorate degree will be developed around 2016.http://smdtex.ensait.fr.

IDEALAB To make clear reference to the joint doctoral training of the partner universities, there are common application and selection procedures, common quality assessment and programme monitoring, a joint curriculum and a common research training programme cumulating in a joint degree. http://em-idealab.com

TEEME Joint degrees will be awarded to TEEME candidates by Kent, FU Berlin and CU Prague. http://www.teemeurope.eu/.

EMJD-DC EMJD-DC will initially award double degrees; however, a task will study pathways to the implementation of a Joint Degree. http://emjd-dc.eu.

MACOMA http://www2.uca.es/serv/catedra-unesco/erasmusmundus/macoma/index.htm.

NeuroTime Each $\mathrm{PhD}$ candidate will perform a research project in collaboration between two or three partner institutions. The Universities of Amsterdam, Strasbourg, Jerusalem and TIFR-deemed University of Bangalore deliver a Joint Degree. The universities of Basel and Freiburg award double PhD Degrees (unless a new agreement about Joint degree is signed before the end of the $\mathrm{PhD}$ period). The title of the $\mathrm{PhD}$ degree will include the official titles of the respective universities, with the mention "Joint Degree" or "Double degree". http://www.neurotime-erasmus.org.

SMART Successful completion of the PhD programme will be awarded a joint and double Doctoral Degree in River Science. https://www.riverscience.it/.

LAST-JD The partners deliver a joint degree between four partners and a double title with the other. http://www.last-jd.eu . 
As mentioned in the Horizon 2020 Work Programme 2014-2015 (legal framework of the REPBIOTECH application), "enrolment in a doctoral programme and the creation of a joint governance structure - with joint admission, selection, supervision, monitoring and assessment procedures" was mandatory for the EJD modality. Therefore, to fulfill these requirements and for the joint supervision of the $15 \mathrm{PhD}$ students enrolled, a joint governance structure was designed to enable smooth management and coordination of all the aspects of the programme with a minimum of bureaucracy. Specifically, three main committees were established:

1) Supervisory Board, responsible for the fairness of the selection process, the final admission of the candidates, the assignment of the supervisors and research topics and the assessment of the quality of the PhD process. This board included one member of each beneficiary and partner organisation plus two second-year students.

2) Progress Committees (PC, specific for each student), responsible for the quality of the research and the guidance of the students during the entire length of the programme. These Committees included at least two external advisors from institutions not affiliated with the consortium, in addition to the supervisors and the advisors from the institutions where additionals mobilities were going to be carried out. The compostion of the PCs was decided at the very beginning of the project (kick-off meeting).

3) Thesis Committees (specific for each student), the final jury in front of which each graduate defended his/her thesis. It was arranged according to the European $\mathrm{PhD}$ or Doctor Europaeus/ Europaea rules originating from an informal initiative in 1991 and adopted on June 23rd 1993 by the Confederation of EU Rectors' Conference (now EUA, European Universities Association), but with some modifications, such as the requirement to have a minimum research period of at least one trimester in another European country (6 months in REPBIOTECH, and at least in 2 different countries, from any part of the world).

In addition, the governance structure was completed with the Coordination Management Team, responsible for communication with the European Commission, and the Work Package Leaders, in charge of the research coordination and decisions regarding each Work Package. Also, all partners signed a Consortium Agreement with detailed issues related to administration, intellectual property rights, the management adopted, training policies, mutual recognition of joint $\mathrm{PhD}$ degrees, conflict resolution, gender equality policies, recruitment strategies, and in general any term that they should respect.

\subsection{Problems with the Implementation of the EJD}

Not only were the scientific objectives and the necessary networking activities in each of the 15 REPBIOTECH theses to be developed clearly established and smoothly accomplished from the very beginning, but also the administrative issues with regard to contracts, 
secondments, research costs and mobilities were agreed by the 5 institutions without noteworthy problems. However, there were, indeed, many stones along the way through the EJD that are classified below, according to the 6 main obstacles identified by de Rosa (2010):

3.2.1. Confusion in terminology: this was a main issue among the staff involved in the project, especially the differentiation between the concepts of double, multiple and joint degrees. While initially, during the proposal preparation, all the academics and administrators seemed to talk the same "language", this became a fallacy as the project developed. The already mentioned article by de Rosa (2010) as well as Annex 2 in the report of Aerden \& Lokhoff (2013) are highly enlightening in this context and its reading is recommended to avoid such misundertstandings.

\subsubsection{Resistance towards joint doctoral programmes among academics, departments and} faculties: in our case, this obstacle did not appear at the academic level, perhaps due to the long history of previous collaborations between participants and the mutual trust that prevailed above any other question. In fact, such enthusiastic conviction was transmited towards further hierachies at the University structure, including departments and faculties. The general perception was that most of the European Universities are, today, in agreement about the need (and benefits) of internationalization and this type of programmes are really useful to reach these objectives.

3.2.3. Lack of funding for long-term sustainability: this has become a major issue once the EU grant ended. Only one of the 5 Universities has continued enrolling new students in the programme and another has decided to discontinue awarding the joint degree for students enrolled outside the initial grant period. Although new proposals are being submitted, the dependency on external funds is something that Universities have assumed as normal and puts the sustainability of the EJD at risk.

3.2.4. Different status of doctoral candidates (student or employee) in different institutions: this obstacle did not happen in the framework of REPBIOTECH because all of the students were hired by the hosting Universities according to their national legal requirements.

3.2.5. Legal framework: as inferred from the above issues, the legal frameworks of the 5 institutions awarding the joint degree were highly varied, as shown in Table 2. Some legal frameworks did not allow their Universities to award joint degrees, while other legal frameworks limited the award of a degree to those students that had actually studied at that institution. For this reason, one group of 3 institutions agreed to award a common joint degree while the other group awarded student-based joint degrees, similar to the traditional co-tutelle agreements.

3.2.6. Lack of experiencelexpertise: this was also a repetitive aspect throughout the whole project, mainly from the administration side, since every new matter arising needed to be 
studied at different levels. In contrast, no scientific or academic issues arose, since all the supervisors were experienced researchers with a long track of international scientific cooperation and history of PhD students successfully graduated.

Table 2. Summary of the legal situation about Joint Doctorates at the 5 Universities awarding degrees in REPBIOTECH programme.

\begin{tabular}{|c|c|c|c|c|}
\hline \multirow[t]{2}{*}{ University } & \multicolumn{2}{|c|}{$\begin{array}{l}\text { Legal processes to deliver a } \\
\text { Joint Diploma available }\end{array}$} & \multirow[t]{2}{*}{$\begin{array}{l}\text { Legal Entity awarding PhD } \\
\text { Diplomas (signatory) }\end{array}$} & \multirow{2}{*}{$\begin{array}{c}\text { Joint } \\
\text { Diplomas } \\
\text { awarded }\end{array}$} \\
\hline & At 2015 & At 2019 & & \\
\hline 1 & No* & $\begin{array}{l}\text { Yes, regulations } \\
\text { were adapted. }\end{array}$ & $\begin{array}{l}\text { Ministry (Rector in the name of } \\
\text { the Head of the State) }\end{array}$ & Yes**. \\
\hline 2 & No* & No & University (Rector) & Yes $* * *$ \\
\hline 3 & No* & No & $\begin{array}{l}\text { University (President of the } \\
\text { University) }\end{array}$ & Yes $* * *$ \\
\hline 4 & No* & Yes & University (Rector) & Yes **. \\
\hline 5 & Yes* & Yes & University (Rector) & Yes **. \\
\hline
\end{tabular}

\section{Final results and concluding remarks}

The information provided above, both from the personal experience of the authors and from the collection of available data on public websites, shows that, still today, there is a huge gap to be overcome before the existence of Joint International/European Doctorates can be considered an everyday reality. Although various attempts have been performed in the last 20 years, there is still a long way to go for Higher Education institutions to integrate all aspects of the programmes, and to make them something different than an additional certificate. It is expected that the recent initiative for building up the so called European Universities $^{8}$, going beyond existing higher education cooperation models, can finally achieve the long-term ambition of a real and integrated European Education Area, where students and staff can move between countries within a common legal framework. For this, the drive of the academics encouraging their administrations to move forward is the crucial point.

\footnotetext{
${ }^{8}$ European Universities Initiative - European Commission. Retrieved January 20, 2020, from https://ec.europa.eu/education/education-in-the-eu/european-education-area/european-universities-initiative_en
} 


\section{References}

Aerden , A. \& Lokhoff J. (2013). Framework for Fair Recognition of Joint Degrees. European Consortium for Accreditation in higher education.

De Rosa, AS (2010). Internationalisation of Collaborative Doctorates and Joint European/International Doctorates: requirements and guidelines for each dictinct model. In : A. Klucznik-Töro, K. Bodis \& K. P. Istvan (eds.), From Education to Innovation, IHEPI, (pp. 219-242). Budapest, Hungary: IDResearch Ltd.

European Commission (2018). Report from the commission to the European Parliament, the Council, The European Economic and Social Committee and the Committee of the Regions. Mid-term evaluation of the Erasmus+ programme (2014-2020). (https://eurlex.europa.eu/legal-content/FR/TXT/?uri=COM:2018:50:FIN). 